Ensayo

Los textos publicados son responsabilidad exclusiva de sus autores

\title{
Reflexiones acerca del proceso de edición editorial en Guatemala
}

\section{Reflections about the process of editorial edition in Guatemala}

\author{
Carlos Roberto Salazar Juárez \\ carl034@gmail.com \\ https://orcid.org/0000-0002-5591-2977 \\ Juan Luis Mejía Recinos \\ juanluismejiar@gmail.com \\ Evelyn Janeth Mejía Recinos \\ evenethmejiar@gmail.com \\ Maestría en Edición Editorial \\ Universidad de San Carlos de Guatemala
}

\section{Referencia del ensayo}

Salazar Juárez, C. R., Mejía Recinos, J. L., Mejía Recinos, E. J. (2021). Reflexiones acerca del proceso de edición editorial en Guatemala. Revista Guatemalteca de Cultura. 1(2), 36-43 DOI 10.46954/revistaguatecultura.v1i2.13

Recibido 15/01/2021

Aceptado 22/06/2021 


\section{Resumen}

El ensayo contiene una reflexión acerca de la experiencia de tres estudiantes con relación al proceso editorial. Debido a que esta tarea conlleva una serie de pasos que tomaría meses de trabajo, se realizó un ejercicio que contempla únicamente el análisis de un manuscrito. El objetivo de la actividad era permitir un primer acercamiento con un texto inédito para sugerir los cambios necesarios para mejorarlo, hacerlo inteligible y que el mensaje llegue de forma clara al lector. Para ello se utilizó una matriz que evalúa aspectos de forma y de fondo de la obra seleccionada. Esta actividad permitió a los autores reflexionar sobre todo el proceso, aunque solo se llevó a cabo la parte de la revisión del manuscrito. Se hicieron sugerencias de mejora principalmente en la forma de presentar el contenido. Entre las propuestas están ampliar el interlineado, buscar una tipografía más redondeada y sin serifa, cambiar capturas de pantalla por diseños propios para asegurar la legibilidad, una selección de colores más atractiva y la revisión general de ortotipografía, puntuación y estructuras gramaticales complejas. Este tipo de ejercicios permite reflexionar acerca de la práctica de la edición.

Palabras clave: reflexiones, proceso editorial, edición

\section{Abstract}

The essay contains the reflections of three graduates based on their experience related to the editorial process. Due to the impossibility of carrying out all of the steps in the given time, the descriptions rely on the analysis of a manuscript. The objective of this task was to allow a very first contact with an unpublished text, in order to suggest needed changes to improve it, make it understandable, and assure that the message is clearly delivered to the reader. To achieve this goal, an analysis matrix was used to evaluate different aspects, which include both, content and form of the document. This practice allowed the authors to reflect on the whole process, even if only the review part of the manuscript was elaborated. Suggestions for improvement were made mainly in the way of presenting the content of the manuscript. Among the proposals made, increase the line spacing, use a rounder font without serif, change screenshots for native designs from the document, this way we can guarantee legibility, also an attractive color palette and a general review in spelling, punctuation and grammatical structures. This kind of practices allow us to reflect about the entire editorial edition process.

Keywords: editorial process, reflections, edition 


\section{Introducción}

El mundo de la edición es amplio y conlleva una serie de aspectos que deben tenerse en cuenta para que las publicaciones finales tengan una calidad aceptable y para que satisfagan a los lectores. En primera instancia, es necesario que los editores reflexionen acerca de su labor y de cómo deberían ocurrir los procesos que tienen a su cargo. En este caso, a partir de un ensayo reflexivo y participativo con más de un autor, se logran plasmar las reflexiones acerca de la importancia que tienen tanto la academia como la experiencia laboral para un editor.

Los autores del ensayo cuentan con distintas experiencias e intereses que permiten ampliar la perspectiva en las reflexiones y descripciones que aparecen a continuación. Sin embargo, desde la perspectiva de un lingüista, una arqueóloga y un psicólogo, el análisis del contexto guatemalteco permite acercar distintos públicos a las lecturas adecuadas. Ya sea para generar publicaciones literarias, investigaciones académicas o educativas, es importante conocer antes los procesos de cara al contexto en donde se llevan a cabo. De igual forma, se contempla la necesidad de que los editores se acoplen a las nuevas tecnologías y las características de los usuarios.

Para facilitar la comprensión de las ideas, se ha estructurado el ensayo de forma secuencial. Es decir, se describen y analizan aspectos importantes de cada paso en el proceso editorial, desde el manuscrito hasta su publicación. A partir de ahí, pueden identificarse las áreas en las que la realidad no siempre se apega a los textos y que es importante mantener ejercicios como la discusión profesional, la actualización y la lectura permanente. De esta forma, los editores no dejan de construir un juicio crítico, el cual utilizarán para llevar a término cada proceso editorial del que formen parte.

\section{Contenido}

Para la redacción de este ensayo se tomó como fuente principal de información, la experiencia en el análisis de un texto inédito. Los materiales utilizados para realizar esta práctica fueron el manuscrito que se revisó y una matriz que sirvió para evaluar diversos aspectos de forma y de fondo del documento seleccionado. Asimismo, en este instrumento se anotaron las sugerencias de modificaciones que se consideraron pertinentes para mejorar la claridad del mensaje de la obra. Este proceso se llevó a cabo aprovechando la formación académica previa y la experiencia laboral de los autores; la multidisciplinariedad del equipo permitió una perspectiva más amplia y objetiva acerca de los cambios que el documento requería. 
Tabla 1. Análisis editorial de un manual gastronómico.

\begin{tabular}{|c|c|}
\hline Organización & $\begin{array}{l}\text { El texto está bien organizado. Va de lo teórico a lo práctico; sin embargo, hace } \\
\text { falta una mejor selección de colores. Se podrían diferenciar fundamentos, técnicas, } \\
\text { metodología y actividades, usando distintos colores de fondo para los subtítulos. A } \\
\text { ser un documento pensado para formato digital, se sugiere incluir hipervínculos a los } \\
\text { títulos que aparecen en el índice. }\end{array}$ \\
\hline $\begin{array}{l}\text { Estructura } \\
\text { (márgenes, } \\
\text { interlineado) }\end{array}$ & $\begin{array}{l}\text { Se sugiere rediseñar la portada por otro más atractivo y que comunique un mensaje } \\
\text { acorde con el contenido del manual. Es imperante ampliar el interlineado para que la } \\
\text { lectura sea más relajada y cómoda. Además, la tipografía seleccionada no es la más } \\
\text { dinámica; se propone un tipo de letra más redondeada, siempre sin serifa. Corroborar } \\
\text { que no queden líneas viudas ni huérfanas, y que los títulos aparezcan en la página que } \\
\text { les corresponde. }\end{array}$ \\
\hline $\begin{array}{l}\text { Imágenes, } \\
\text { diagramas, tablas } \\
\text { y organizadores } \\
\text { gráficos }\end{array}$ & $\begin{array}{l}\text { Tanto las imágenes como los diagramas y organizadores gráficos necesitan ser } \\
\text { rediseñados, asegurando una mejor calidad para que sean legibles y atractivos } \\
\text { Evitar capturas de pantalla con texto porque este se pierde por la baja resolución. Es } \\
\text { necesario verificar que cada imagen incluya un título y un pie de imagen, y que no } \\
\text { queden en páginas distintas. }\end{array}$ \\
\hline $\begin{array}{l}\text { Lenguaje } \\
\text { (gramática, } \\
\text { ortotipografía, } \\
\text { sintaxis) }\end{array}$ & $\begin{array}{l}\text { En general, la gramática, sintaxis y ortografía son correctas. Sin embargo, conviene } \\
\text { que un revisor verifique el adecuado uso de signos de puntuación, la precisión en la } \\
\text { escritura y las estructuras gramaticales complejas. Considerando el tipo de texto, se } \\
\text { sugiere sintetizar la información, especialmente en las tablas y organizadores gráficos. }\end{array}$ \\
\hline
\end{tabular}

Fuente: elaboración propia (2021).

Una vez analizados los resultados, es posible resaltar que cuando se habla del proceso editorial, se debe tener en cuenta una serie de factores que van más allá de una secuencia de pasos que llevan a la publicación de una obra. De hecho, en este proceso intervienen elementos contextuales, tales como el público al que se dirige, el perfil del autor, los parámetros de la casa editorial, el presupuesto, y claro está, el equipo de profesionales que se encargarán de cada etapa. Esteves y Vanzulli (2002) explican que una editorial está constituida por un equipo de personas que utilizan diversos recursos y conocimientos para alcanzar los objetivos trazados; además, se apegan a las normas internas de la institución.
Para hablar de la selección del manuscrito es importante hacer referencia a una figura que convendría tener en los países latinoamericanos: el agente literario. Este personaje es el que tiene el criterio para identificar manuscritos que puedan ser de interés para las distintas casas editoriales. Su primera lectura es crucial para que el autor sea tomado en cuenta y que su texto llegue a las manos correctas para seguir el proceso de publicación. Sin embargo, contextos menos favorecidos para una industria como esta, no facilitan la existencia de esta figura ya que entran en juego los factores económicos y la apertura de las editoriales. Según López y Malumián (2016), es común que el editor idealice la obra, como un producto diferente a todos, pero en realidad, como cualquier otro, necesita ser vendido para que sea rentable. 
Las grandes editoriales en Guatemala suelen publicar libros que forman parte de su plan editorial del año y en muy pocas ocasiones se interesan por publicar a autores desconocidos que llevan su manuscrito. En primer lugar, por cuestiones de negocio, este proceso no es de beneficio para el autor; el asunto suele desembocar en privilegios para la editorial y riesgos de pérdida para el autor. Muchos otros optan por la autopublicación: un proceso igualmente costoso y en el que se descuidan muchos detalles ya que el proceso no es orientado por un equipo profesional multidisciplinario. Ante esto, ¿cuántos de los libros autopublicados realmente pueden ser adquiridos por los lectores meta?

A diferencia de las editoriales grandes, es decir que cuentan con un capital inicial alto, y que haya un respaldo financiero para poder sostenerse durante un tiempo considerable, la mayoría de las editoriales emergentes en Guatemala cuentan con un capital pequeño. Es importante medir la rentabilidad de los títulos que se pretenden publicar y en estas primicias basar la proyección de publicaciones, ya sean autopublicaciones o de cualquier otra intención. Para evaluar la gestión de una editorial, la unidad temporal de medida nunca debe ser menor a tres años y no se debe esperar que el retorno de la inversión -si alguna vez se produce- ocurra antes. "Convertirse en editor es fácil, lo difícil es seguir siéndolo", sostiene Stanley Unwin (1964).

Es necesario hacer mención que la publicación, más allá de los libros, no es una práctica cultural establecida en Guatemala. Es difícil considerar la publicación como un medio de supervivencia en un contexto en el que las personas no tienen hábito de lectura y cuyo poder adquisitivo es limitado. Así, aunque las publicaciones no necesariamente se hagan impresas (lo cual aumenta su valor en el mercado), es un público muy reducido el que está dispuesto a pagar por un documento en línea, porque no relacionan el valor de la obra con la autoría sino con el producto tangible. Por estos factores, las obras que se digitalizan se comparten sin tener en cuenta los derechos de autor y esto hace que el oficio del escritor sea poco rentable. Al respecto, Unwin (1964) dice que si el editor está buscando enriquecerse, se equivoca de profesión; debe esperar su recompensa en algo diferente a la remuneración económica.

Por otro lado, cuando se hace una autoría por encargo (algo bastante común en editoriales educativas) el editor se enfrenta con dos problemas en paralelo: un cronograma exigente y diversidad de autores. En este sentido, el editor debe atender al primer borrador de forma inmediata y con retroalimentación general. De esta manera, el autor puede abordar nuevamente su tarea y el editor invierte su tiempo en otras autorías.

La edición del texto puede dividirse en fases para asegurarse de que se estén contemplando todos los aspectos tanto de forma como de fondo. Si bien el editor no debería encargarse de la parte ortotipográfica, en la práctica sí se deben contemplar una revisión del lenguaje, aunque el corrector de estilo afine la precisión de las palabras, ortografía, puntuación, etcétera. En este sentido, se debe empezar por la revisión estructural del documento; posterior a ello, se puede hacer la revisión de contenido y lo recomendable en todo caso, es dejar comentarios para que el autor sea quien haga las enmiendas. Aquí puede aprovecharse para sugerir cambios en los que, debido al lenguaje, las ideas no se comprenden claramente. Una vez se han hecho estas vueltas de revisión, el editor hace los últimos retoques en cuanto al lenguaje para enviarlo a corrección de estilo. 
El término "corrección de estilo" es debatible. En algunos casos, como las producciones educativas, los manuales, la comunicación institucional, entre otros, sí es importante mantener una serie de parámetros que marcan el estilo de la empresa. Sin embargo, cuando se trata de la redacción de un texto literario o libre, el corrector debe respetar el estilo del autor; así sea que se incluyan errores intencionales en ortografía, redundancias, cacofonías, etcétera. Este es un trabajo que requiere de un criterio amplio y muy enfocado en la naturaleza de la obra, ya que es un error común que los correctores de estilo hagan cambios debido a que el estilo de escritura no se asemeja al tradicional o propio del corrector. Por otro lado, el corrector de estilo debe ser una persona con conocimiento amplio de la lengua, así como poseer un alto criterio para desempeñar su labor; debe ser cuidadoso al leer el todo y cada parte.

Los materiales impresos o digitales están destinados a un público específico. Es decir, no puede pretenderse que un mismo libro encaje para todas las edades, contextos e intereses. Por lo anterior, estas características del público meta deben ser tomadas en cuenta al momento de diseñar la experiencia del lector; desde la elección del interlineado, la tipografía, el color del papel, imágenes, empastado... cada detalle cuenta para construir el producto final. Así, el proceso de maquetación y diagramación puede ser el que hable de la calidad de la obra: si un texto no es cómodo, el lector abandonará su lectura a pesar de que el contenido y el lenguaje sean adecuados.

Como parte de las etapas finales, el revisor de pruebas, idealmente, es una persona que no ha tenido contacto con el material y esto permite tener una visión fresca de la obra. En ocasiones, los errores están presentes, pero los ojos del editor y del corrector de estilo se acostumbran a verlos y no los reconocen como tales. Entonces, el revisor de pruebas, además de asegurarse de que no haya ríos, viudas, huérfanas, dobles blancos, páginas sin cuadrar; será el último que verá el documento antes de darlo por terminado y listo para imprimirse.

Aunque la divulgación del material no es el trabajo directo del editor de mesa, el director editorial debe encargarse de que la obra encuentre su lugar en el mercado. Es decir, este paso es de los más importantes, ya que todos los esfuerzos que se hicieron hasta ahora se ven recompensados hasta que los lectores correctos reciben el texto publicado y disfrutan de él. La edición y el trabajo del editor no terminan cuando el libro sale de imprenta y es colocado en libreras. Si un buen libro, con una edición cuidada, no se vende, es responsabilidad de la editorial por una mala ejecución de la estrategia comercial. Se tienen dos elementos en la ejecución, que son diferentes e interrelacionados: que se tenga una distribución adecuada, y la prensa, la difusión y la comunicación, tanto del libro como de la editorial. Según lo indican López y Malumián (2002) el aporte de periodistas, programas de radio y televisión especializada en la temática de los textos, es importante para que el libro sea comentado y leído. Esto no garantiza que el libro sea un éxito; sin embargo, es un proceso esencial para comercializar un título.

\section{Conclusión}

Como se mencionó en los párrafos anteriores, existen más editores que el que interviene los textos. En este sentido, las actividades de un editor pueden ser radicalmente distintas a las 
de otra persona que se reconoce como tal. En casas editoriales pequeñas, las tareas se mezclan y el mismo director editorial resulta ser el coordinador y el editor de mesa. Por otro lado, en empresas más grandes, el director editorial es el que gestiona los aspectos generales del proyecto: su concepción, su conceptualización, la coordinación de los equipos interdisciplinarios, la aprobación del presupuesto, etcétera.

Más adelante, el coordinador editorial gestiona los recursos de manera más específica y centrada en la comunicación directa entre los autores, editores, correctores y demás participantes. Su labor es la de asegurar el seguimiento de cronogramas y de que cada miembro del equipo realice una labor consecuente con la idea general del proyecto. Si bien no hace ediciones directas en los textos, sí debe asegurarse de que los textos cumplen con los requerimientos; es por ello que debe tener contacto directo con los editores junior (de mesa) para que se hagan los ajustes correspondientes.

Finalmente, el editor de mesa es el que tiene a su cargo una parte del proyecto; el contacto con el autor y el tratamiento del texto directamente. Es en él en quien recae mayor responsabilidad del contenido y de la forma. Aunque hay más tipos de editores, estos tres son los que representan la ejecución de las tareas desde lo general a lo más específico. No obstante, es importante resaltar que los editores que tratan directamente con los textos no necesariamente están entrenados para cualquier tipo de obra; por el contrario, su experiencia los especializa en algún tipo de texto: educativos, científicos de un área, notas periodísticas, redes sociales, etcétera. De hecho, lo importante es que el editor tenga la responsabilidad ética de contar con los criterios y conocimientos que lo respaldan para abordar un documento.
Redes sociales como Facebook, Instagram y Twitter entre otras, son herramientas que ahora los editores pueden utilizar para la difusión. Los motivos son su fácil accesibilidad, el bajo costo y la alta interacción con los usuarios y entre ellos. Estas herramientas digitales permiten que la brecha entre el lector y la editorial se haga pequeña. Se podría determinar que la prensa sigue siendo necesaria, pero es responsabilidad de la editorial mantener herramientas como las redes sociales activas, aportando a los canales de difusión del proyecto editorial.

En otro orden de ideas, es crucial hacer la reflexión acerca de la edición en la actualidad. La producción de contenidos en la web sobrepasa lo que históricamente se ha publicado en libros impresos. La información se genera a velocidades difíciles de imaginar y es por esto que el editor debe acoplarse al mundo digital. Muchas de las comunicaciones que antes se hacían impresas se han dejado en formatos digitales y cada vez más, con la inclusión de recursos interactivos y audiovisuales. Ante esto, es necesario que, aunque haya publicaciones que no se centren en los textos, haya un editor que valide el contenido y el lenguaje antes de hacer las publicaciones en la red.

\section{Agradecimientos}

Para la redacción de este ensayo es importante mencionar la asesoría previa del maestro Eduardo Villalobos. Tanto la matriz de análisis utilizada, como muchas de las reflexiones que se presentan en este ensayo parten los conocimientos que este profesional de la edición compartió con los autores. 


\section{Referencias}

Esteves, F. y Vanzulli, J. (2002). Administración de una empresa de cultura. Paidós, Buenos Aires.

López, H. y Malumián, V. (2016). Independientes, ¿de qué?, Hablan los editores de América Latina. Fondo de Cultura Económica, Ciudad de México.

Unwin, S. (1964). La verdad sobre el negocio editorial. Juventud, Barcelona.

\section{Sobre los autores}

\section{Carlos Roberto Salazar Juárez}

Es profesor de Lengua y Literatura, licenciado en Letras y estudiante de la Maestría en Edición Editorial de la Universidad de San Carlos de Guatemala. Tiene estudios complementarios en Humanidades digitales, derechos humanos y ciencia de datos.

\section{Juan Luis Mejía Recinos}

Es licenciado en Psicología Clínica y Consejería Social y licenciado en Educación y Aprendizaje. En el campo de la edición ha trabajado en autoría, edición y coordinación editorial para dos casas editoriales, a nivel nacional y global. Actualmente es estudiante de la Maestría en Edición Editorial de la Universidad de San Carlos de Guatemala.

\section{Evelyn Janeth Mejía Recinos}

Es licenciada en Arqueología y actualmente estudiante de la Maestría en Edición Editorial de la Universidad de San Carlos de Guatemala. Tiene estudios complementarios dentro y fuera del país sobre conservación del patrimonio cultural. Tiene experiencia como autora y editora en dos casas editoriales y actualmente coordina las actividades y los asuntos editoriales del Seminario de Procesos de Industrialización en Guatemala.

\section{Copyright (c) Carlos Roberto Salazar Juárez, Juan Luis Mejía Recinos y Evelyn Janeth Mejía Recinos.}

Este texto está protegido por una licencia Creative Commons 4.0.

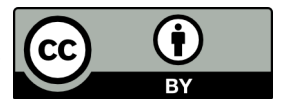

Usted es libre para compartir, copiar y redistribuir el material en cualquier medio o formato y adaptar el documento, remezclar, transformar y crear a partir del material para cualquier propósito, incluso comercialmente, siempre que cumpla la condición de atribución: usted debe reconocer el crédito de una obra de manera adecuada, proporcionar un enlace a la licencia, e indicar si se han realizado cambios. Puede hacerlo en cualquier forma razonable, pero no de forma tal que sugiera que tiene el apoyo del licenciante o lo recibe por el uso que hace. 